\title{
MEMORIAL SOBRE A TRAJETÓRIA ESCOLAR BÁSICA DE MARIA DE NAZARÉ CENA FARIAS
}

\author{
Maria de Nazaré Cena Farias ${ }^{1}$
}

Resumo: O presente texto trata do memorial sobre a trajetória escolar de Maria de Nazaré Cena Farias, ex-integrante do Programa Conexões de Saberes. Tem como objetivo apresentar os passos percorridos desde o início da educação básica até a entrada à UFPA e quais os principais entraves de estudantes das comunidades populares adentrarem o ensino superior público. A memória foi usada como principal referência para construção do material. Em seus resultados, apresenta os esforços individual e coletivo para que de fato a educação seja uma questão de direito e não de privilégio de poucos.

\section{As Raízes}

Sou Maria de Nazaré Cena Farias, nome dado a mim através de minha mãe Maria Raimunda Cena e meu pai Francisco da Silva Farias, em homenagem a padroeira maior dos paraenses, Nossa Senhora de Nazaré. Tenho 25 anos de idade, sou a caçula de uma família de onze irmãos.

Minha história de vida é marcada por períodos de necessidade econômica muito, porém sempre com muita luta e esperança em dias melhores.

Nasci em um parto feito em casa, às margens do Rio Gipurú, município de Breves, apesar de ter vindo morar muito pequena para a cidade, ainda preservo minhas raízes, de cabocla marajoara, e me orgulho muito disso.

Meus pais, lavradores e analfabetos, criaram grande parte de meus irmãos, trabalhando na roça fazendo farinha, cortando cana, plantando macaxeira, arroz, melancia e outros frutos, os quais trocavam por mercadorias como: café, açúcar, feijão, charque, fumo e outros, nos barcos ou na maioria das vezes no comércio do "patrão".

A vida que levávamos morando no interior era muito trabalhosa, mas tínhamos o básico para sobreviver: teto, comida, e água. No entanto minha mãe queria mais para seus filhos, ela não se conformava de ver seus filhos crescendo do mesmo jeito que ela, sem saber pelo menos ler e escrever. Foi então que ela decidiu que queria que seus filhos estudassem, mas ela não contava

\footnotetext{
${ }^{1}$ Acadêmica* de Licenciatura Plena em Pedagogia pela Universidade Federal do Pará, Campus de Breves, e-mail: conexoesmulticampi@yahoogrupos.com.br

* atualizado pela última vez em 2008.
}

Revista PET Interdisciplinar e Programa Conexões /UFPA On-line. Ed. Especial - 2017, BELÉM/ PA - ISSN 2447-097X 
com a aprovação de meu pai, que acreditava que nós iríamos morrer de fome na cidade, pois como que uma família com onze filhos e pais analfabetos iria sobreviver numa cidade onde tudo é comprado.

Foi então que aconteceu um episódio que fez com que meu pai fosse obrigado a sair juntamente com sua família daquele local onde vivera por mais de quarenta e cinco anos. Nos morávamos de um lado do rio e os patrões moravam do outro lado, eles criavam muitos porcos, e vez por outra os porcos se soltavam, atravessam o rio, e fuçavam todo o roçado dos meus pais; meus pais sempre avisaram aos patrões para prendê-los mas constantemente isso acontecia. Então em um iluminado dia, quando minha mãe e meus irmãos mais velhos chegaram ao roçado presenciaram os porcos fuçando toda a plantação do roçado, um de meus irmãos em um momento de raiva matou todos os porcos que ali estavam, eram mais ou menos oito em seguida mandaram para seus patrões. Esses, por sua vez, ficaram muito aborrecidos com o acontecido e nos expulsaram do interior de onde morávamos. Foi assim que chegamos até Breves, através de um ato, visto por alguns como bravura e por outros como insanidade; daquele em diante até aqui e aqui estamos há vinte e três anos todos vivos, a muito custo com muita dificuldade.

\section{O Recomeço}

Não foi fácil recomeçar a vida fora de seu lugar de origem, a cidade se revela um verdadeiro calvário para quem não tem o mínimo de instrução, porém meus pais sempre foram muito batalhadores, e com muito trabalho pesado conseguiram manter com o mínimo todos seus filhos, meu pai trabalhando em serrarias de madeira e minha mãe trabalhando como doméstica, e lavando roupa pra fora, na casa de pessoas que exploram seu trabalho.

Felizmente minha mãe conseguiu o que tanto almejava que foi conseguir que todos seus filhos estudassem, muitos tiveram somente o ensino básico, pois tiveram que trabalhar para ajudar no sustento da família, outros até conseguiram terminar o ensino médio mais pelos mesmos motivos também tiveram que abandonar os estudos. Somente eu tive a oportunidade de continuar estudado, mesmo estudado, nunca perdi o foco nos meus estudos, pois tinha e tenho a consciência que só através da educação se pode ter um futuro digno.

Em todos esses anos tive inúmeros percalços em minha vida estudantil, hoje com a clareza e o conceito que tenho de educação, percebo que tive um ensino base muito fraco, tive muita dificuldade de ingressar na universidade e de permanecer nela, inúmeros fatores também

Revista PET Interdisciplinar e Programa Conexões /UFPA On-line. Ed. Especial - 2017, BELÉM/ PA - ISSN 2447-097X 
contribuíram para dificultar a minha vida acadêmica, como o financeiro, por exemplo, mas hoje tenho clareza que a falta de uma base consistente nos ensinos fundamental e médio me renderam as maiores dificuldades. Pelas três vezes que fiz a prova do vestibular pude ter a noção exata do quanto me fazia falta todos os dias perdidos de aula, pela falta de professor ou por qualquer outro motivo. No entanto o sonho de poder fazer um curso de graduação tornava-se ainda maior dentro de mim, foi então que com muita dedicação e superando as condições financeiras precárias de quem ganhava apenas um salário mínimo, que com todos os descontos se reduzia a menos que isso eu me matriculei em um cursinho pré-vestibular. Tal atitude, no entanto, acarretou problemas para minha família, pelo fato de que meus pais necessitavam da minha ajuda financeira para se sustentar o mês todo, mais com todas as dificuldades que tivemos neste período conseguimos superar e tudo isso só veio me dá mais força para estudar incansavelmente e conseguir ser aprovada no vestibular. A notícia da aprovação foi sem dúvida a mais emocionante que já recebi até então. Então num estado completo de felicidade, comemorei como uma louca juntamente com a minha família e com meus amigos, pois o que para alguns é pouco, para mim e pela trajetória de vida da minha família é a realização de um sonho.

\section{A Vida Acadêmica}

Ao começar a estudar na Universidade Federal do Pará, é que vim saber o que realmente é o curso que eu havia escolhido, pois até então eu não sabia de fato e de direito do que ele se tratava, pois eu só o tinha escolhido porque era o único que dava pra conciliar com meu trabalho da época que era numa loja de confecções.

O contato mais próximo que estabeleci desde então com o curso de Licenciatura Plena em Pedagogia e com a universidade como um todo me fizeram ter uma visão completamente diferente da educação e principalmente da sociedade da qual fazemos parte; quando estamos de fora vemos que muita coisa está errada, mas não temos o pensamento crítico para avaliar, julgar e emitir nossa opinião. Os conhecimentos adquiridos no decorrer destes quatro anos em que estou no curso de graduação só vieram somar para a minha vida, enquanto educadora que agora sou e enquanto membro desta sociedade. A academia me abriu novos horizontes fez com que eu ficasse mais receptiva a novos conhecimentos, e que percebesse também que a universidade, apesar de ser o "baluarte" do conhecimento defendido por muitos, ainda está aquém das expectativas dos

Revista PET Interdisciplinar e Programa Conexões /UFPA On-line. Ed. Especial - 2017, BELÉM/ PA - ISSN 2447-097X 
acadêmicos, a falta de estrutura física e humana e de incentivo a pesquisa e a extensão são carências gravíssimas que ainda temos que superar.

Desmistificado o universo fantástico que eu fazia da universidade, percebi que aquele antigo sonho de entrar dignamente no mercado de trabalho ainda estava distante de acontecer, a politicagem ainda é um fator que influencia muito, principalmente na área da educação, e isso se torna muito evidente em cidades pequenas como Breves. A gama de educadores de qualidade que o município já perdeu para outros estados vizinhos é grandiosíssima, a única opção para os que querem permanecer trabalhando na cidade sem concurso publico é fechar os olhos aos desmandos políticos. Felizmente o concurso público agora é obrigatório para todos os municípios, e já é uma realidade também para o município de Breves. No entanto a politicagem continua, pois grande parte dos educadores que passaram no concurso ainda continua aguardando serem chamados, esse se constitui no meu caso.

\section{O Projeto}

Das mudanças que o ingresso na universidade me proporcionou posso citar como valiosíssima a minha entrada no Projeto Conexões de Saberes, o complemento que este enquanto projeto de pesquisa e extensão tem me oferecido enriquece e elucida ainda mais os meus conhecimentos e sentimentos em relação à importância do meu papel social enquanto universidade e enquanto cidadã desta sociedade. Como tal, nós como membros deste projeto temos tentado diminuir a distância que se estabeleceu durante séculos entre a universidade e as camadas populares da sociedade. Partindo deste princípio, o projeto conexões de saberes assume um caráter ímpar na relação universidade/sociedade, buscando desta forma dar um retorno mínimo pra esta sociedade que a mantém.

Sou bolsista do projeto há dois anos, sei da importância singular deste na discussão do acesso e permanência de alunos oriundos de camadas populares na universidade. Discutir esse assunto há muito tempo ignorado pela elite das universidades e pelos órgãos governamentais, tem um caráter especial para mim, por eu ser de origem popular e saber das dificuldades que se enfrenta para entrar e permanecer na universidade pública, por experiência própria, sei da relevância de se estar discutindo e tentando achar novos caminhos para a inclusão dessas pessoas no ensino superior. Essa bandeira da política de acesso e permanência que a UFPA juntamente com as demais universidades públicas nas quais o projeto está inserido, vem lutando pela

Revista PET Interdisciplinar e Programa Conexões /UFPA On-line. Ed. Especial - 2017, BELÉM/ PA - ISSN 2447-097X 
inclusão se faz extremamente necessária, haja vista que a grande maioria dos acadêmicos das universidades públicas hoje é de classe média e alta, essa é uma realidade que não podemos deixar passar despercebido.

Este se tornou o desafio do projeto, tentar buscar alternativas juntamente com a Academia, sociedade Civil e Órgão do Governo para amenizar essa disparidade existente dentro da universidade pública. Assim como os outros campi da UFPA, Campus do Guamá e de Castanhal, que o projeto está inserido, o campus de Breves o qual faço parte, como acadêmica do curso de pedagogia e como bolsista do projeto Conexões de Saberes tem contribuído, incansavelmente para amenizar esse índice de exclusão, juntamente com a coordenação local $d o$ conexões e os bolsistas, promovemos vários eventos para tentar conscientizar a comunidade acadêmica da importância da inclusão para se ter uma sociedade mais justa e igualitária. No sentido de tentar diminuir esse distanciamento que existe entre universidade/sociedade, nos anos de 2006 e 2007, o conexões Breves organizou o cursinho popular, cursinho pré- vestibular gratuito para a comunidade, com a parceria do Campus Breves; dispondo de seu espaço físico o conexões organizou aulas gratuitas com professores voluntários da rede municipal para 150 pessoas oriundas de camadas populares que estivessem interessadas em fazer o vestibular, foi a priori uma experiência que deu certo a não ser pelas adversidades financeiras encontradas pelos alunos. Até antes de sair o resultado da isenção as turmas estavam completamente lotadas, 50 pessoas em cada turma, logo após o resultado praticamente metade ou mais da metade dos alunos desistiram, pois não ganharam isenção e nem dispunham de dinheiro para inscrição. Essa é a triste realidade que se apresenta não só em Breves mas em todo Brasil.

Acredito que a abrangência da temática do acesso e permanência ainda está longe de atingir a demanda esperada pelo projeto e seus idealizadores, no entanto o fato de estar levando esta discussão até órgãos Federais como o ministério da Educação, assim como a coordenação das universidades publicas mais bem conceituada do país, já é de grande relevância, mostrar a essas entidades que não estamos de olhos fechados para as desigualdades e exclusão que afetam a educação superior. É por esses motivos que acredito no projeto conexões de saberes e precisamos que este permaneça vivo, alertando a sociedade acadêmica, civil e governamental para o fato das desigualdades que vem acontecendo ao longo dos séculos no ensino superior.

O possível término deste programa viria acarretar um retrocesso em todo este processo de construção de uma nova mentalidade do que realmente seja educação de qualidade para todos.

Revista PET Interdisciplinar e Programa Conexões /UFPA On-line. Ed. Especial - 2017, BELÉM/ PA - ISSN 2447-097X 
Além deste papel social que o projeto desempenha, ele também proporciona a seus integrantes bolsas mensais, ajuda de custo para acadêmicos de origem popular e que não estejam trabalhando, como eu, por exemplo, que já estava desempregada há mais de seis meses e que agora posso adquirir os materiais necessários para meus estudos acadêmicos bem como, ajudar a minha família. Esta bolsa serve de apoio para mim principalmente agora que a minha família está prestes a aumentar, pois no mês de março serei mãe, essa ajuda será substancial para minha família. Enquanto eu não me formar e conseguir uma colocação digna no mercado de trabalho, estarei contando sempre com o projeto e tudo que ele tem a me oferecer tanto profissionalmente como conscientemente e financeiramente.

Assim sendo eu como acadêmica e cidadã só tenho a agradecer e parabenizar os idealizadores deste projeto pela iniciativa de tentar mostrar, a olho nu, a realidade das universidades públicas do país, apesar dos embargos que este projeto vem sofrendo, a duras penas estamos conseguindo conscientizar a comunidade elitizada da universidade pública do país.

Revista PET Interdisciplinar e Programa Conexões /UFPA On-line. Ed. Especial - 2017, BELÉM/ PA - ISSN 2447-097X 